\title{
Major complications during negative pressure wound therapy in poststernotomy mediastinitis after cardiac surgery
}

\author{
Rainer Petzina, MD, PhD, ${ }^{a}$ Malin Malmsjö, MD, PhD, ${ }^{\mathrm{b}}$ Christof Stamm, MD, $\mathrm{PhD},{ }^{\mathrm{a}}$ and \\ Roland Hetzer, MD, $\mathrm{PhD}^{\mathrm{a}}$
}

Objective: Negative pressure wound therapy is the first-line treatment modality for poststernotomy mediastinitis in many heart centers. The aim of this study was to analyze major complications and possible preventive methods during negative pressure wound therapy in patients with deep sternal wound infections.

\begin{abstract}
Methods: We retrospectively analyzed 69 consecutive patients treated with negative pressure wound therapy for poststernotomy mediastinitis between June 2006 and September 2009.
\end{abstract}

\begin{abstract}
Results: Five (7.2\%) patients sustained major complications during negative pressure wound therapy. Bleeding from coronary artery venous bypass grafts was observed in 4 patients and fulminant bleeding from an infected homograft of the ascending aorta was observed in 1 patient during routine dressing changes of the negative pressure wound therapy system.
\end{abstract}

Conclusions: Bleeding is the major complication during negative pressure wound therapy for poststernotomy mediastinitis. Covering the heart with several layers of paraffin gauze is a necessary protective maneuver but cannot completely prevent major complications during negative pressure wound therapy. All operative procedures, including dressing changes, should be performed in the operating room under optimal hygienic and monitoring conditions to increase the salvage rate and to guarantee optimal surgical and anesthesiologic conditions in case of negative pressure wound therapy-related complications. (J Thorac Cardiovasc Surg 2010;140:1133-6)

Negative pressure wound therapy (NPWT) is nowadays the first-line treatment modality for poststernotomy mediastinitis after cardiac surgery in many heart centers. ${ }^{1,2}$ The reported early mortality in poststernotomy mediastinitis after coronary artery bypass grafting (CABG) varies between $8 \%$ and $43 \%$ with conventional treatment modalities. ${ }^{3,4}$ NPWT has resulted in excellent clinical outcomes with a dramatic reduction in mortality and sternal reinfection rates compared with conventional treatment. ${ }^{5,6}$ The technique entails application of negative pressure by controlled suction to a sealed airtight wound. The continuous vacuum enables the drainage of excessive fluid and debris, removal of wound edema, reduction in bacterial count, enhanced granulation tissue formation, and sternal stability. ${ }^{7-9}$ Recent publications have reported cases of major bleeding complications caused by rupture of the free wall of the right ventricle during NPWT. ${ }^{10-12}$ The present study was aimed to analyze major complications and possible preventive methods during NPWT in patients with poststernotomy mediastinitis at our institution.

\footnotetext{
From Deutsches Herzzentrum Berlin, ${ }^{\mathrm{a}}$ Berlin, Germany, and Lund University Hospital, ${ }^{\mathrm{b}}$ Lund, Sweden.

Disclosures: None.

Received for publication Jan 6, 2010; revisions received March 19, 2010; accepted for publication June 7, 2010; available ahead of print Sept 10, 2010.

Address for reprints: Rainer Petzina, MD, PhD, Deutsches Herzzentrum Berlin, Augustenburger Platz 1, 13353 Berlin, Germany (E-mail: petzina@web.de). $0022-5223 / \$ 36.00$

Copyright (c) 2010 by The American Association for Thoracic Surgery doi:10.1016/j.jtcvs.2010.06.063
}

\section{MATERIALS AND METHODS}

The present study is a retrospective analysis of 69 consecutive patients with poststernotomy mediastinitis treated with NPWT who were operated on at Deutsches Herzzentrum Berlin between June 2006 and September 2009. Until 2006, patients with poststernotomy mediastinitis were treated with conventional therapy. This includes surgical debridement, removal of all sternal wires, drainage and irrigation, transposition of the greater omentum, and restabilization of the sternum. Since 2006, we have used NPWT for 69 consecutive patients with deep sternal wound infections after surgical debridement, removal of all sternal wires, and irrigation. The surface of the right ventricle is protected by several layers of paraffin gauze (Figure 1). The first layer of polyurethane foam is placed between the sternal edges, and a second layer is fitted over the first layer and secured to the surrounding skin. The wound is sealed with a transparent adhesive drape, and the evacuation tube is connected to a continuous vacuum source $(-125 \mathrm{~mm} \mathrm{Hg})$. The wound filler is changed every 2 to 4 days in the operating room $(\mathrm{OR})$ with redebridement and reirrigation, if necessary. Secondary wound closure is performed with rewiring of the sternum after the mediastinitis is successfully treated, as indicated by negative microbiological testing of the mediastinal swabs and when a reduction is seen in leukocytes and C-reactive protein levels.

Mediastinitis is a devastating complication in cardiac surgery, with an incidence of $1 \%$ to $5 \%$. We have 20 years' experience treating more than 700 patients with poststernotomy mediastinitis, with a mediastinitis rate of less than $3 \%$.

The main cardiac operation in our study was CABG or CABG in combination with valve procedures $(85.5 \%)$. The remaining patients underwent isolated valve replacements, ascending aorta replacement, or both The median EuroSCORE value was 7, with a range between 1 and 18 . Deep sternal wound infections with the need for surgical treatment occurred on average 22.4 days (range, 7-72 days) after the cardiac procedure. During NPWT, $5.5 \pm 1.6$ operative procedures were necessary to complete the mediastinitis treatment (initial NPWT operation, 3.5 dressing changes, and secondary wound closure). The mean duration of NPWT was 17 days (range, 6-47 days) before definite secondary sternal closure was 


\section{Abbreviations and Acronyms}

$\mathrm{CABG}=$ coronary artery bypass grafting

$\mathrm{NPWT}=$ negative pressure wound therapy

$\mathrm{OR}=$ operating room

performed. The mortality rate was $5.8 \%$, with a sternal reinfection rate of $2.9 \%$ in 69 consecutive patients with poststernotomy mediastinitis treated with NPWT.

\section{RESULTS}

The in-hospital mortality was 5.8\% (4 patients) in all 69 consecutive patients with deep sternal wound infections treated with NPWT. These 4 patients died of septic multiorgan failure on the intensive care unit, and they did not have any NPWT-related complications. Five $(7.2 \%)$ other patients, however, sustained major NPWT-related complications. Bleeding from coronary artery venous bypass grafts was observed in $4(5.8 \%)$ patients (Figure 2$)$ and fulminant bleeding from an infected homograft of the ascending aorta was observed in $1(1.4 \%)$ patient during routine dressing changes of the NPWT system.

During routine dressing changes of the NPWT system in the OR, both the polyurethane foam and the layers of paraffin gauze protecting the right ventricle were removed. In 4 patients bleeding of a venous bypass graft to the right coronary artery was seen and could be controlled with sutures (7-0 polypropylene). Neither electrocardiographic changes nor hemodynamic alterations or increased creatine kinase, creatine kinase $\mathrm{MB}$, or troponin levels were observed intraoperatively or postoperatively. In all 4 patients NPWT was successfully continued. Secondary wound closure was performed in all 4 patients with rewiring of the sternum, and the patients were discharged in good condition.

One patient had received an aortic homograft for valve endocarditis. Postoperatively, a deep sternal wound infection occurred and was treated with NPWT. After removal of the paraffin gauze during routine dressing changes in the OR, fulminant arterial bleeding of the infected homograft of the ascending aorta occurred and could be temporarily stopped by means of manual compression by the surgeon. Because of extreme adhesions in the thoracic cavity, the right femoral vessels were exposed and cannulated for extracorporeal circulation. After heparinization, the patient was operated on during deep hypothermia and cardiac arrest. A small piece of pericardium $(3 \times 3 \mathrm{~cm})$ was sutured to the hole in the aortic homograft of the ascending aorta. Transposition of the greater omentum was performed at the end of the operation with sternal closure. The postoperative course of this patient was uneventful.

We also observed minor complications in several patients caused by NPWT, such as dislocation of the upper layer of

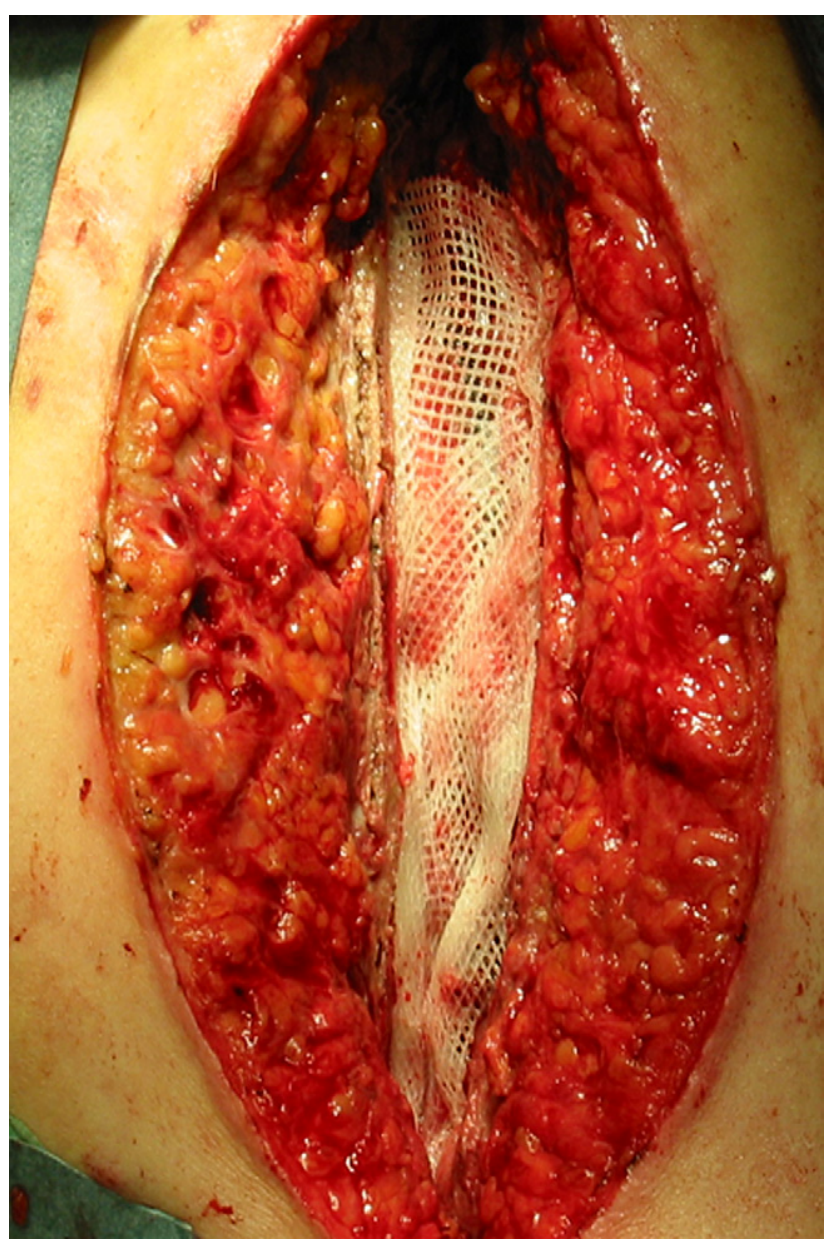

FIGURE 1. Covering of the heart with several layers of paraffin gauze

the polyurethane foam or disconnection of the evacuation tube to the vacuum source, but none of those influenced the clinical course of the patients.

\section{DISCUSSION}

The aim of this study was to analyze major complications and possible preventive methods during NPWT in patients with poststernotomy mediastinitis. Since 2006, NPWT has been the fist-line treatment for deep sternal wound infections at our institution in 69 consecutive patients. We could reduce the mortality rate in patients with mediastinitis from $23 \%$ in the conventional group to $5.8 \%$ in the NPWT group (data not shown). ${ }^{13}$ The main complication is bleeding from a venous bypass graft during dressing changes of the NPWT system, although the hearts were protected with several layers of paraffin gauze.

Recent publications have reported on right ventricular rupture during NPWT for poststernotomy mediastinitis. ${ }^{10-12}$ NPWT caused the heart to be sucked up to the sternum. Malmsjö and colleagues ${ }^{14}$ presented altered position of the heart during NPWT in a pig model assessed by magnetic resonance imaging and demonstrated that sharp edges of the 


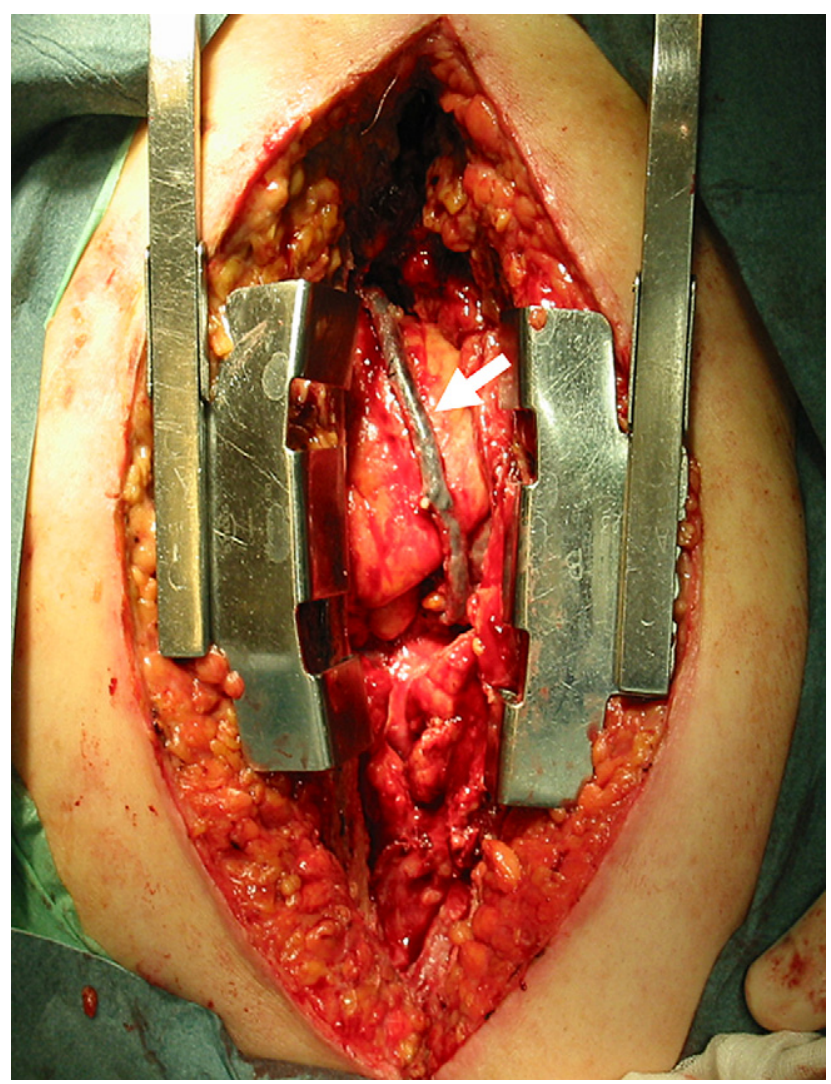

FIGURE 2. Prominent and vulnerable venous bypass graft (indicated by arrow) to the right coronary artery visible on the surface of the right ventricle

sternum jutted into the right ventricle. This might be the reason for heart rupture during NPWT. Otherwise, the problem of right ventricular rupture has also occurred in patients with mediastinitis treated with conventional therapy, such as mediastinal irrigation in the era before NPWT. ${ }^{15,16}$ The mediastinal infection leads to extreme vulnerability of tissue. The combination of a constantly moving organ, like the heart, and vulnerable tissue results in bleeding complication independent of the treatment applied for mediastinitis. Protection of the free wall of the right ventricle with several layers of paraffin gauze is an easy and inexpensive maneuver that can reduce the incidence of heart rupture and should be a standard procedure. Nevertheless, $4(5.8 \%)$ of 69 patients treated with NPWT at our institution had arterial bleeding from a bypass graft, even though the heart and bypass grafts were covered with paraffin gauze. In the future, it should be possible to further minimize major bleeding complications during NPWT by inserting a rigid barrier as a protective shield over the heart, which is described by Malmsjö and colleagues. ${ }^{14}$

Dislocation of the upper polyurethane foam as a minor complication can be avoided by suturing the edge of the upper foam to the surrounding skin. Disconnection of the evacuation tube from the vacuum source will be detected by the NPWT system and set off an alarm, but this should also be checked routinely.

Because of the convenience of this novel treatment modality, it is not unusual that dressing changes of the NPWT are performed on the ward in the patient's room with inadequate hygiene and monitoring. At our institution, all dressing changes are performed in the OR. This has led to good results for our patients with deep sternal wound infections and especially for the 5 patients with NPWTrelated major bleeding complications. Also, this procedure improves the clinical outcome of the patients because of a higher salvage rate and the possibility of redebridement of infected tissue.

In conclusion, NPWT results in excellent clinical outcome for poststernotomy mediastinitis. The major negative effect of NPWT is life-threatening bleeding. Covering the heart with several layers of paraffin gauze is a protective maneuver but cannot entirely prevent major complications during NPWT. All operative procedures, including dressing changes, should be performed in the OR under optimal hygiene and monitoring conditions to increase the salvage rate and to guarantee optimal surgical and anesthesiologic conditions in case of NPWT-related complications.

We thank Anne M. Gale, ELS, for editorial assistance and Henryk Siniawski, $\mathrm{MD}, \mathrm{PhD}$, and Evgenij Potapov, $\mathrm{MD}, \mathrm{PhD}$, for their valuable comments on this manuscript.

\section{References}

1. Argenta LC, Morykwas MJ. Vacuum-assisted closure: a new method for wound control and treatment: clinical experience. Ann Plast Surg. 1997;38:563-77.

2. Fleischmann W, Lang E, Kinzl L. [Vacuum assisted wound closure after dermatofasciotomy of the lower extremity]. Unfallchirurg. 1996;99:283-7.

3. Stahle E, Tammelin A, Bergstrom R, Hambreus A, Nystrom SO, Hansson HE. Sternal wound complications-incidence, microbiology and risk factors. Eur J Cardiothorac Surg. 1997;11:1146-53.

4. Ridderstolpe L, Gill H, Granfeldt H, Ahlfeldt H, Rutberg H. Superficial and deep sternal wound complications: incidence, risk factors and mortality. Eur J Cardiothorac Surg. 2001;20:1168-75.

5. Sjogren J, Gustafsson R, Nilsson J, Malmsjo M, Ingemansson R. Clinical outcome after poststernotomy mediastinitis: vacuum-assisted closure versus conventional treatment. Ann Thorac Surg. 2005;79:2049-55.

6. Domkowski PW, Smith ML, Gonyon DL Jr, Drye C, Wooten MK, Levin LS, et al. Evaluation of vacuum-assisted closure in the treatment of poststernotomy mediastinitis. J Thorac Cardiovasc Surg. 2003;126:386-90.

7. Morykwas MJ, Argenta LC, Shelton-Brown EI, McGuirt W. Vacuum-assisted closure: a new method for wound control and treatment: animal studies and basic foundation. Ann Plast Surg. 1997;38:553-62.

8. Petzina R, Gustafsson L, Mokhtari A, Ingemansson R, Malmsjo M. Effect of vacuum-assisted closure on blood flow in the peristernal thoracic wall after internal mammary artery harvesting. Eur J Cardiothorac Surg. 2006;30:85-9.

9. Mokhtari A, Petzina R, Gustafsson L, Sjogren J, Malmsjo M, Ingemansson R. Sternal stability at different negative pressures during vacuum-assisted closure therapy. Ann Thorac Surg. 2006;82:1063-7.

10. Ennker IC, Malkoc A, Pietrowski D, Vogt PM, Ennker J, Albert A. The concep of negative pressure wound therapy (NPWT) after poststernotomy mediastinitis - a single center experience with 54 patients. J Cardiothorac Surg. 2009;4:5.

11. Sartipy U, Lockowandt U, Gabel J, Jideus L, Dellgren G. Cardiac rupture during vacuum-assisted closure therapy. Ann Thorac Surg. 2006;82:1110-1. 
12. Abu-Omar Y, Naik MJ, Catarino PA, Ratnatunga C. Right ventricular rupture during use of high-pressure suction drainage in the management of poststernotomy mediastinitis. Ann Thorac Surg. 2003;76:974-5.

13. Petzina R, Hoffmann J, Navasardyan A, Malmsjö M, Stamm C, Unbehaun A, et al. Negative pressure wound therapy for post-sternotomy mediastinitis reduces mortality rate and sternal re-infection rate compared to conventional treatment. Eur J Cardiothorac Surg. 2010;38:110-3.

14. Malmsjö M, Petzina R, Ugander M, Engblom H, Torbrand C, Mokhtari A, et al. Preventing heart injury during negative pressure wound therapy in cardiac surgery: assessment using real-time magnetic resonance imaging. $J$ Thorac Cardiovasc Surg. 2009;138:712-7.

15. Arbulu A, Gursel E, Camero LG, Asfaw I, Stephenson LW. Spontaneous right ventricular rupture after sternal dehiscence: a preventable complication? Eur J Cardiothorac Surg. 1996;10:110-5.

16. Partanen J, Verkkala KA, Karhunen PJ, Kauppila R, Nieminen MS. Profuse mediastinal haemorrhage due to mediastinitis after sternotomy. Report of three cases and review of the literature. Scand J Thorac Cardiovasc Surg. 1996;30: $167-73$. 